\title{
ESTADO DE USO E CONSERVAÇÃO DE MOTOSSERRAS COM MOTORES DE COMBUSTÃO INTERNA
}

\author{
Jaqueline Ottonelli $^{*}$, Catize Brandelero ${ }^{2}$, Valmir Werner ${ }^{2}$, José Fernando Schlosser $^{2}$, Marcelo Silveira de Farias ${ }^{3}$ \\ 1Programa de Pós-graduação em Engenharia Agrícola (PPGEA), Universidade Federal de Santa Maria (UFSM), 97105-900, Santa \\ Maria, RS, Brasil. \\ ${ }^{2}$ Departamento de Engenharia Rural (DER), Centro de Ciências Rurais (CCR), UFSM, Santa Maria, RS, Brasil. \\ 3 Departamento de Ciências Agronômicas e Ambientais, UFSM - Campus Frederico Westphalen, 98400-000, Frederico Westphalen, \\ RS, Brasil. \\ *E-mail: jaqueline.ottonelli@gmail.com
}

Recebido em: 26/11/2019

Aceito em: $27 / 07 / 2020$

\section{RESUMO}

As motosserras são amplamente utilizadas no meio rural. Para mantê-las em bom estado de uso e conservação, faz-se necessário realizar a manutenção de forma adequada e dar instruções para o correto manuseio. Neste trabalho, as motosserras são caracterizadas de acordo com as classes de potência, e dos conjuntos o motor, a transmissão e o corte. Foi utilizado um questionário para coletar informações sobre as 73 motosserras usadas por produtores rurais na região central do estado do Rio Grande do Sul. Como resultado verificou-se que $63 \%$ das motosserras avaliadas pertenciam à classe de potência Média, das quais 82,6\% apresentavam o ângulo de afiação dos dentes da corrente fora do padrão recomendado. Destaca-se que, a limpeza da vela de ignição e a inversão do sabre foram realizadas em $70 \%$ das motosserras avaliadas, e que $45 \%$ das máquinas apresentavam desgaste no conjunto coroa/pinhão. No conjunto de corte as motosserras da classe Média, evidencia-se que 82,6\% das unidades verificadas apresentavam ângulo de afiação dos dentes da corrente fora do padrão recomendado. As motosserras das classes Média e Pesada apresentaram a maior quantidade de problemas. Nota-se que, a falta de manutenção pode reduzir a eficiência operacional e a vida útil da motosserra.

Palavras-chave: Máquinas florestais. Produtor rural. Manutenção.

\section{Introdução}

De acordo com a Norma Regulamentadora NR-12, a motosserra é uma serra motorizada de empunhadura manual [1]. Esta máquina possui constituição relativamente simples, formada basicamente por conjunto motor, transmissão e conjunto de corte $[2-4]$.

As motosserras são máquinas versáteis e têm vasta utilização, tanto para fins domésticos, em atividades leves, quanto no meio rural e florestal, em atividades consideradas médias e pesadas, que exigem motores com maior potência [5]. Esta máquina serve para cortar, desramar, traçar e podar árvores [6]. No mercado brasileiro, são ofertados 155 modelos de motosserras de 14 marcas comerciais, que atendem às finalidades domésticas e profissionais [7].

Para manter o desempenho da motosserra, faz-se necessário adequada manutenção e operação, que pode evitar reparos de maior grandeza, otimizar o tempo efetivo em trabalho e a vida útil da máquina, além de proporcionar segurança para o usuário [8-5].
Para tanto, recomendam-se vistorias antes de iniciar o trabalho, durante a operação e periodicamente [9-10-4].

A utilização de motosserras sem conhecimento técnico torna impossível monitorar como estas são usadas, o quê, com conhecimento técnico insuficiente e falta de consciência de risco ambiental, pode resultar em práticas perigosas [11].

As informações sobre a manutenção e o estado de conservação das motosserras são praticamente inexistentes, quando comparados com as pesquisas relacionadas à ruído e vibração destas [12-15].

Este trabalho teve como objetivo caracterizar motosserras com motores de combustão interna, quanto a sua classe de potência e ao conjunto motor, transmissão e corte, em uso por produtores rurais na região central do estado do Rio Grande do Sul. 


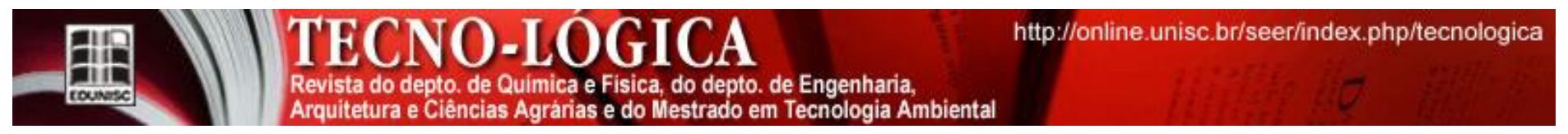

\section{Metodologia}

Realizaram-se visitas pela equipe do projeto, acompanhadas por um técnico da Empresa Estadual de Assistência Técnica e Extensão do Rio Grande do Sul (EMATER/RS). As verificações se estenderam nos municípios de Dona Francisca,
Faxinal do Soturno, Ivorá, Júlio de Castilhos e Santa Maria (Figura 1). A região de estudo se caracteriza por pequenas propriedades rurais, com base na produção agrícola e animal.
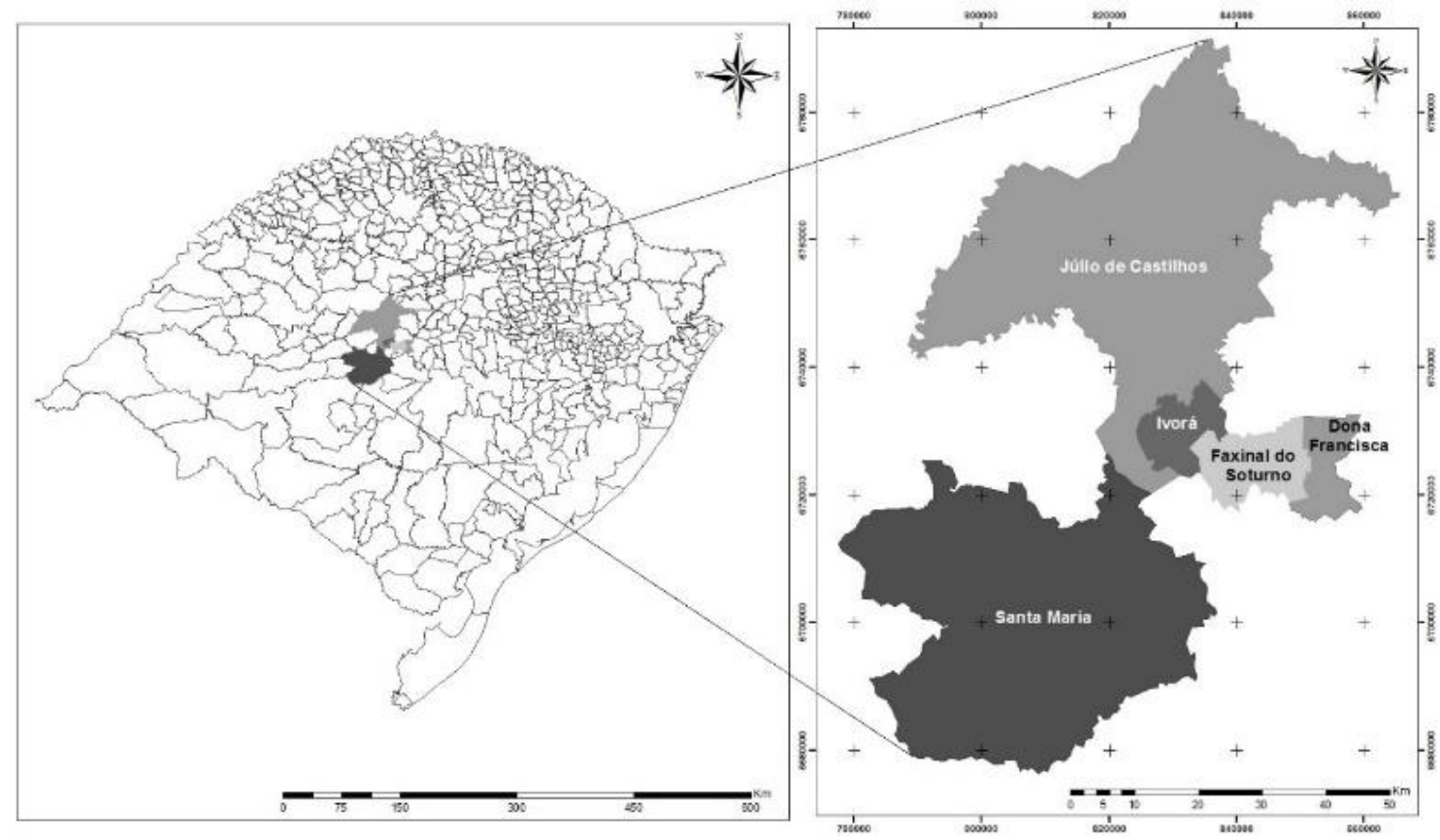

Figura 1 - Posicionamentos dos municípios amostrados. Adaptado de IBGE [16].

Elaborou-se um questionário Tabela 1, o qual foi aplicado por meio de visitas técnicas nas propriedades rurais, após aceite do proprietário. Os dados estão estruturados de forma a apresentar informações que caracterizam as motosserras utilizadas pelos produtores e organizados quanto à sequência dos conjuntos motor (filtro de ar, vela de ignição, cordão de arranque e carburador), transmissão (embreagem e coroa/pinhão) e corte (sabre e corrente).
Tabela 1. Questionário aplicado aos usuários, por meio de visitas técnicas em propriedades rurais da região Central do estado do Rio Grande do Sul.

\section{Conjunto motor}

O filtro de ar está presente? $\square$ Sim $\square$ Não

Como realiza a limpeza do filtro de ar?

$\square$ Não realiza $\square$ Ar comprimido $\square$ Gasolina $\square$ Ar comprimido + gasolina

Realiza a calibração da vela de ignição? $\square$ Sim $\square$ Não

Realiza a limpeza da vela de ignição? $\square$ Sim $\square$ Não

Possui folga no cordão de arranque? $\square$ Sim $\square$ Não

Realiza as regulagens do carburador? $\square \operatorname{Sim} \square$ Não

O carburador está regulado? $\square$ Sim $\square$ Não

\section{Conjunto transmissão}

Funcionamento da embreagem: $\square$ Ruim $\square$ Bom

Existe desgaste no coroa/pinhão: $\square$ Sim $\square$ Não

\section{Conjunto de corte}

Realiza a limpeza das canaletas do sabre? $\square$ Sim $\square$ Não.

Existe desgaste da ponteira do sabre? $\square$ Sim $\square$ Não.

Realiza a calibração do limitador de profundidade? $\square$ Sim $\square$ Não

Realiza a inversão do sabre? $\square$ Sim $\square$ Não

Realiza a limpeza dos dutos de lubrificação do sabre? $\square$ Sim $\square$ Não

Qual é o ângulo de afiação da corrente utilizada? $\square 30^{\circ} \square 35^{\circ} \square$ Sem padrão

Quantidade de óleo na corrente: $\square$ Adequada $\square$ Inadequada

Fonte: Ottonelli [5]. 
Após a coleta das informações, realizou-se a classificação das motosserras verificadas, conforme Haselgruber \& Grieffenhagem [9] em três classes de potência: Leve (entre 0,74 e 2,2 kW); Média (entre 2,3 e 3,7 kW) e Pesada (de 3,8 a 5,2 kW). Brandelero et al. [7] afirmam que foi possível classificar as motosserras comercializadas no mercado brasileiro, no ano de 2018, nestas três classes de potência.

Os dados do questionário foram tabulados em planilha eletrônica do Microsoft Excel ${ }^{\circledR}$ e submetidos a uma análise exploratória por meio de utilização descritiva, com uso de frequência percentual, conforme metodologia proposta por Farias et al. [17].

\section{Resultados e discussão}

Nas avaliações das motosserras em uso por produtores rurais, foram verificadas 73 unidades. Posteriormente estas máquinas foram classificadas conforme a sua potência e, assim, enquadradas na classe Leve (20 unidades); Média (46 unidades); e Pesada (7 unidades). Pode-se constatar que as máquinas mais antigas estão sendo substituídas por modelos de menor potência.

No conjunto motor, verificou-se que $5,0 \%$ e $4,3 \%$ das motosserras classificadas como Leve e Média, respectivamente, não apresentavam filtro de ar. Isso ocorre pela falta de conhecimento, quanto à importância desse componente, por parte do produtor rural, visto que o motor de ciclo dois tempos admite no seu sistema de alimentação ar mais combustível e, diante disso, necessita que o ar esteja livre de partículas [18]. Das motosserras que contavam com filtro de ar (Figura 2), 25,0\% e 14,3\% não eram limpos, periodicamente (Figura 3A). Ottonelli [5] infere que a ausência do filtro, bem como a falta de manutenção fazem com que a vida útil da máquina e o rendimento operacional sejam reduzidos, e o consumo de combustível aumentado. Streit et al. [3], inferem que o filtro retém o pó do ar aspirado e, assim reduz o desgaste das peças do motor e mecanismos de acionamento.

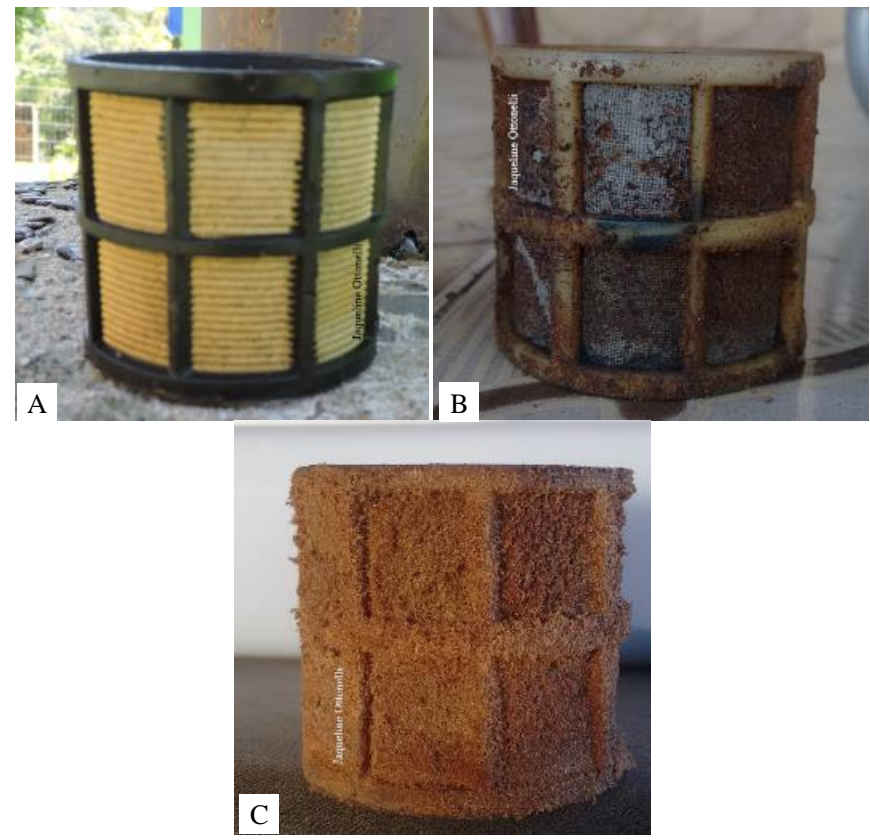

Figura 2 -Filtros de ar das motosserras verificadas: filtro limpo (A); parcialmente limpo (B) e sujo (C). Ottonelli [5].

Quanto à vela de ignição, constatou-se que em mais de 70\% das máquinas, das três classes de potência estavam limpas (sem resíduos de carbonização) e calibradas (espaço padrão entre o eletrodo e o polo). A falta de limpeza da vela pode ocasionar falhas na ignição e no funcionamento do motor, fazendo com que o operador use excessivamente o cordão de arranque. Observou-se $34,8 \%$ e $14,3 \%$ de distensões dos cordões de arranque nas classes Média e Pesada, respectivamente (Figura 3B). A distensão reduz o curso do cordão e dificulta a ignição. Lopes et al. [18] informam que o acúmulo de resíduo indesejado na vela ocorre em função da relação da mistura de combustível incorreta, do carburador desregulado, do filtro sujo ou da borboleta do afogador parcialmente fechada.

Ainda, no conjunto motor, de forma geral, $66,5 \%$ dos usuários afirmaram que realizavam a limpeza e regulagem periódica do carburador. Porém, ao ser verificado constatou-se que 40,0\%; 47,8\%; e 42,9\% das motosserras das classes Leve, Média e Pesada, respectivamente, estavam com o carburador desregulado. Assim, quando a máquina está ligada em marcha lenta, a corrente realiza rotação involuntária, sem o acionamento do acelerador. Neste estado de uso, ocorre problema na combustão, provocado pela mistura incorreta de ar - combustível. Recomenda-se que ajustes sejam realizados conforme o manual de instruções, visto que cada fabricante possui especificações próprias de regulagem. Segundo o fabricante Husqvarna [19], caso o usuário esteja adequadamente instruído, este poderá regular corretamente o carburador, podendo aproveitar a máxima potência da máquina. 


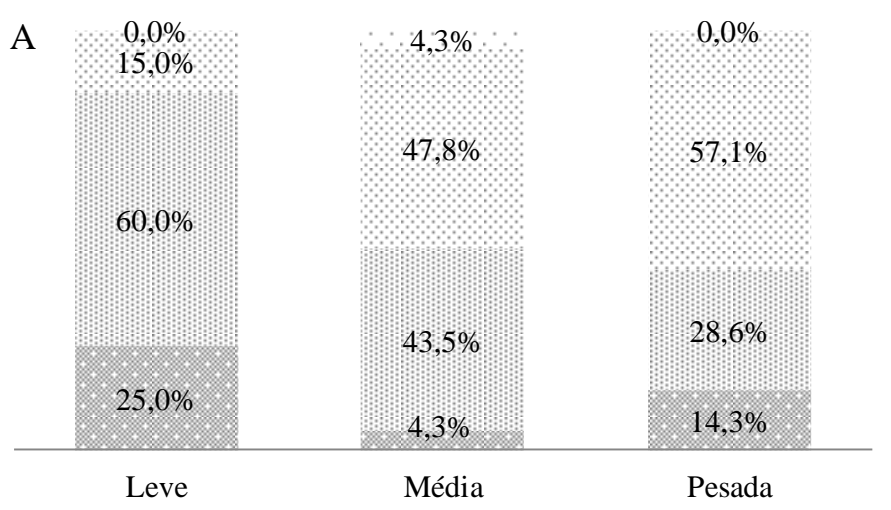

Não realiza Ar comprimido Gasolina Ar compr. + Gasolina

$\mathrm{B}$

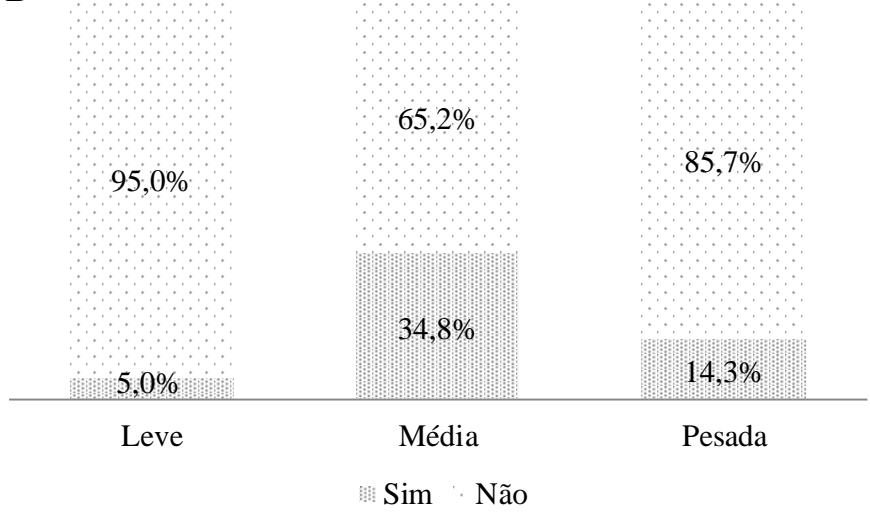

Figura 3 - Caracterização das motosserras avaliadas em função das classes de potência, quanto ao conjunto motor: limpeza do filtro de ar (A) e folga do cordão de arranque (B).

Ao analisar as embreagens e o conjunto coroa/pinhão de todas as classes de potência, $72,0 \%$ das motosserras estavam com a embreagem em bom estado de uso e conservação (Figura 4A); e $45,0 \%$ das máquinas apresentavam desgaste do conjunto coroa/pinhão (Figura 4B).

Quanto ao conjunto de corte, avaliaram-se a limpeza geral, o desgaste, a inversão do sabre e a limpeza dos dutos de lubrificação do sabre. A limpeza do sabre (Figura 5A) não era realizada em $80,0 \% ; 50,0 \%$ e $57,1 \%$ das motosserras Leves, Médias e Pesadas, respectivamente. Pode-se observar na Figura $5 \mathrm{~B}$, com relação ao desgaste, que $80,0 \%$ das motosserras da classe Leve possuem pouco ou nenhum desgaste, caracterizando pouco uso ou utilização em atividades leves. As classes Média e Pesada apresentaram desgaste em $71,7 \%$ e $85,7 \%$, respectivamente. Com relação à inversão do sabre, em média, este procedimento é realizado em $72,7 \%$ das máquinas avaliadas.
A

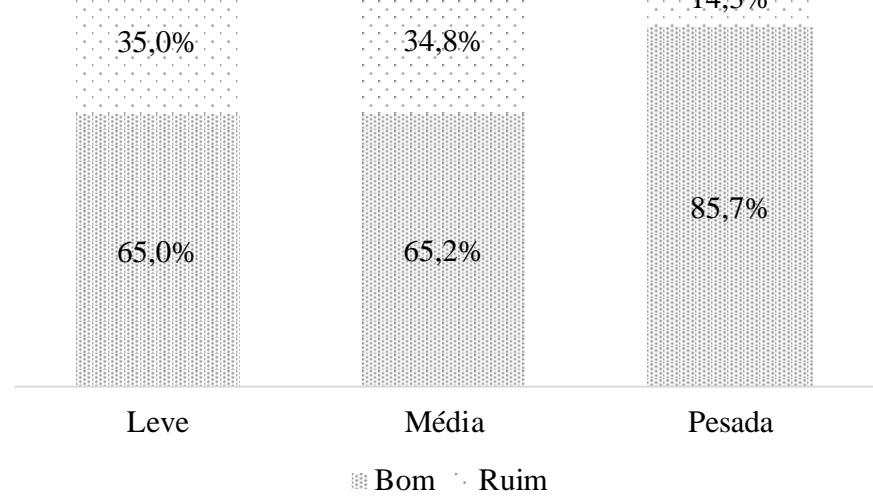

B

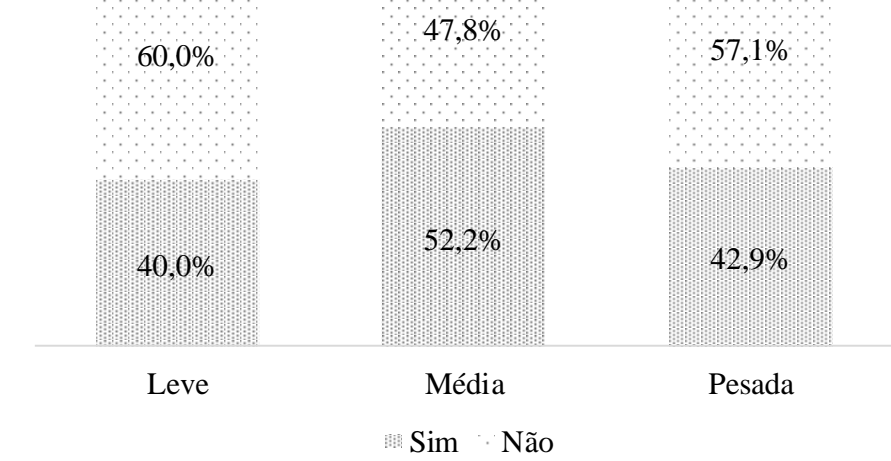

Figura 4 - Caracterização das motosserras avaliadas em função das classes de potência, quanto ao conjunto de transmissão: funcionamento da embreagem (A) e desgaste do conjunto coroa/pinhão (B).

O bom funcionamento do conjunto de corte depende de lubrificação adequada e, assim, pode-se obter máximo rendimento nas operações com a motosserra. Ao analisar os questionários constatou-se que, não era realizada a limpeza dos dutos de lubrificação, em 65,1\% das motosserras da classe Leve e Média. Isso se deve ao fato da falta de instrução aos produtores rurais sobre esta limpeza. Pode-se observar, de forma visual, a insuficiência de óleo lubrificante na corrente, consequência da falta de manutenção do duto. Isso torna a lubrificação inadequada gerando o aquecimento e a dilatação da corrente, logo, recomendase inspecionar periodicamente a lubrificação da corrente, visto que o excesso de óleo lubrificante também é prejudicial ao meio ambiente e para as espécies que possibilitam a condução de rebrote. 
A

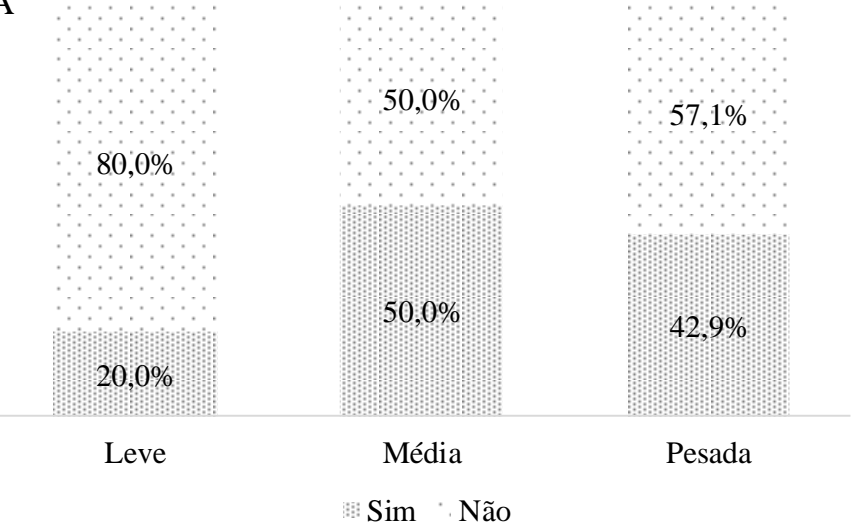

B

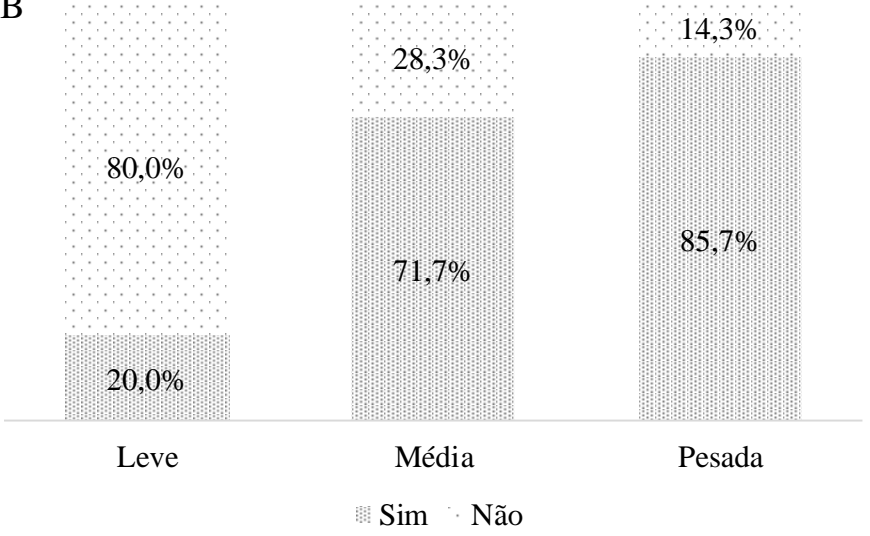

Figura 5 - Caracterização das motosserras avaliadas em função das classes de potência, quanto ao conjunto de corte: limpeza do sabre (A) e quanto ao e desgaste da ponteira do sabre (B).

Quanto à afiação dos dentes da corrente, na média das três classes de potência, $81,1 \%$ dos usuários desconhecem o ângulo padrão recomendado para afiação. Da mesma forma, 70,6\% dos usuários não realizam a calibração do limitador de profundidade, podendo resultar na redução do rendimento operacional e da vida útil da corrente.

\section{Conclusões}

Nas motosserras apontadas: de classes Média e Pesada, foi encontrado maior quantidade de problemas, referente ao estado de uso e conservação. Quanto ao conjunto motor, nas três classes de potência, têm-se inconformidades em níveis similares. $\mathrm{Na}$ transmissão, destaca-se o desgaste do conjunto coroa/pinhão. Ademais, no conjunto de corte, os problemas estão relacionados ao desgaste do sabre e a limpeza dos dutos de lubrificação. Estas aferições evidenciam que a falta de manutenção pode reduzir a eficiência operacional, bem como a vida útil da motosserra.

\section{Agradecimentos}

Os autores agradecem ao apoio financeiro da Coordenação de Aperfeiçoamento de Pessoal de Nível Superior (CAPES) Código de Financiamento 001.

\section{STATE OF USE AND CONSERVATION OF CHAINSAWS WITH INTERNAL COMBUSTION ENGINES}

\begin{abstract}
The chainsaws are widely used in rural area. To keep them in a good state of use and maintenance it is necessary to carry out maintenance in an appropriate way. In this research chainsaws were characterized according to power classes and the motor, transmission and cutting assembly. We used a questionnaire to collect information from 73 chainsaws in use by rural producers. As result, it was verified that $63 \%$ of evaluated the chainsaw belong to the middle class power, these $82,6 \%$ presented the angle of sharpening of the chain teeth out of the recommended standard. It should be noted that the cleaning of the spark plug and the inversion of the saber were carried out in $70 \%$ of the chainsaws evaluated and $45 \%$ of machines showed wear in crown/pinion assembly. In the cutting set the chainsaws of the Middle class, it is evident that $82.6 \%$ of the verified units had sharpening angle of the chain teeth outside the recommended standard. Chainsaws of the middle and heavy classes presented the greatest number of problems. It should be noted that lack of maintenance can reduce the operational efficiency and the service life of the chainsaw.
\end{abstract}

Keywords: Forest machines. Smallholder. Maintenance.

\section{Referências}

[1] BRASIL. Ministério do Trabalho e Emprego. Segurança no trabalho em máquinas e equipamentos: NR-12. 2011. Disponível em: <http://www.guiatrabalhista.com.br/legislacao/nr/nr12.htm>. Acesso em: 28 Mai. 2019 .

[2] CIVIDINI, R. Elementidi tecnologia forestale. Bolonha. Edagricole, 1983. 463p.

[3] STREIT, M.; et al. Mecanização florestal. In: NAGY, J. L. (Coord.). Manual do técnico florestal; apostilas do Colégio Florestal de Irati. Campo Largo, Ingra S.A., 1986, 479p.

[4] VERLAG EUROPA-LEHRNITTEL. Fachkunde LandundBaumaschinentechnik. Haan-Gruiten. 2016, 832p.

[5] OTTONELLI, J. Caracterização do uso e estado de conservação de motosserras de ciclo Otto 2 tempos. 2017. 72f. Dissertação (Mestrado em Engenharia Agrícola) - Programa de Pós-graduação em Engenharia Agrícola, Universidade Federal de Santa Maria.

[6] TORRIJOS, Y. A. et al. Apeo de árboles com motosierra. Espanha: Ediciones Paraninfo, S.A. 2012. 146p. 
[7] BRANDELERO, C. et al. Caracterização dos critérios técnicos para seleção de motosserras e eletrosserras. Tecno-lógica, v.23, n.1, p.01-07, 2019. Disponível em: <https://online.unisc.br/seer/index.php/tecnologica/article/view/12154/7895>. Acesso em: 28 Mai. 2019. DOI: 10.17058/tecnolog.v23i1.12154.

[8] MIALHE, L. G. Manual de Mecanização Agrícola. São Paulo, SP: Ceres, 1974. $301 \mathrm{p}$.

[9] HASELGRUBER, F.; GRIEFFENHAGEN, K. F. G. Motosserras, mecânica e uso. Porto Alegre: Metrópole, 1989. 136p.

[10] STIHL, A. Manejo Seguro e Rentável com Motosserras. São Leopoldo, RS: Centro de Treinamento STIHL, 2004. 56p. (Cadernotécnico).

[11] STAWICKI, T.; SEDLAK, P. Study of the impacto of lubricant type on selected operational parameters of a chainsaw used in beech timber cutting. Derewno, v. 59, n. 196. 2016. DOI: 10.12841/wood.1644-3985.121.12.

[12] CUNHA, I. A. et al. Avaliação de ruído e vibração em motosserra: resultados parciais. Bragantia, Campinas, v. 57, n. 1, p., 1998. Disponível em: $<$ http://www.scielo.br/scielo.php?script=sci_arttext\&pid=S0006-

87051998000100022\&lng=en\&nrm=iso>. Acesso em: 11 Ago. 2016. http://dx.doi.org/10.1590/S0006-87051998000100022.

[13] FIEDLER, N. C. Análise de posturas e esforços despendidos em operações de colheita florestal no litoral norte do Estado da Bahia. 1998. 103 f. Tese (Doutorado em Ciências Florestais) - Universidade Federal de Viçosa, Viçosa, 1998.

[14] FIEDLER, N. C. et al. Avaliação das condições do ambiente de trabalho em atividades de poda de árvores. Cerne, Lavras, v. 13, n. 1, p. 19-24, jan./mar. 2007.

[15] SOUZA, A. P. et al. Production targets for workers in forest harvesting. Revista Árvore, Viçosa, v. 39, n. 4, p. 713-722, ago. 2015. Disponível em $<$ http://www.scielo.br/scielo.php?script=sci_arttext\&pid=S0100-

67622015000400713\&lng=pt\&nrm=iso>. Acesso em: 11 ago. 2016. [http://dx.doi.org/10.1590/0100-67622015000400014].

[16] IBGE. Instituto Brasileiro de Geografia e Estatística. Divisão Regional do Brasil. Disponível em: <ftp://geoftp.ibge.gov.br/organizacao_do_territorio/divisao_regional/divisao_regi onal_do_brasil/divisao_regional_do_brasil_em_regioes_geograficas_2017/mapas 143_regioes_geograficas_rio_grande_do_sul.pdf $>$. Acesso em: 18 mai.2017.

[17] FARIAS, M. S. et al. Critérios técnicos para seleção de pulverizadores autopropelidos comercializados no mercado brasileiro. Ciência Rural, v.45, n.5, p.939-942, 2015. Disponível em: <http://www.scielo.br/pdf/cr/v45n5/1678-4596cr-cr20141179.pdf $>$. Acesso em: 28 Mai. 2019. DOI: 10.1590/0103$8478 \mathrm{cr} 20141179$.

[18] LOPES, E. S., et al. Operação e manutenção de motosserras: manual técnico. Viçosa, MG: Aprenda Fácil, 2001.

[19] HUSQVARNA, AB. Manual de instruções de uso: 61, 268, 272XP. Suécia. 40 p. 2004. 